\title{
AdOLESCÊNCIA: EFEITOS DA CIÊNCIA NO \\ CAMPO DO SUJEITO
}

\author{
Fernanda Costa Moura*
}

\section{Resumo}

Este artigo apresenta a análise das manifestações da crise adolescência na correlação que estas mantêm com o funcionamento social contemporâneo como indicador privilegiado para pensar a operação da ciência e seus efeitos no campo do sujeito. A análise parte do exame da incidência da ciência sobre a linguagem como domínio a partir do qual o sujeito se constitui. Aborda questôes próprias da clínica psicanalítica com adolescentes - tais como a dificuldade de elaboração de uma referência à alteridade e seus impasses diante do sexo e a morte -, refletindo sobre a vinculação destas dificuldades com o que é desencadeado pelas transformações do discurso e do laço social constitutivas da prática da ciência.

Palavras-chave: psicanálise, adolescência, ciência, sujeito, contemporaneidade

\section{AbSTRACT}

\section{ADOLESCENCE: EFFECTS OF SCIENCE OVER THE SUBJECT}

The present paper focuses on the manifestations of the so called adolescence crisis related to the contemporary social order, to analyze the effects of science on the field of the subject. Starting with the exam of the transformations science imposes to language and taking language as constitutive of the subject, the paper approaches some frequent issues of the psychoanalytical clinic held with adolescents - such as the difficulties with otherness, or the subjective position of the young towards sex and death. The relationship those issues might have with the operations performed by science which transform the order of discourse is discussed

Keywords: psychoanalysis, adolescence, science, subject, contemporary culture

* Psicanalista, membro do Tempo Freudiano Associação Psicanalítica; Pesquisadora docente em programa de fixação apoiado pela FAPERJ, Programa de Pós-Graduação em Teoria Psicanalítica, IP/UFRJ. 
A ciência está presente, em nosso mundo, de um modo que ultrapassa em muito tudo o que se possa evocar como efeito de conhecimento. Costumamos pensar a ciência sempre pela perspectiva do ganho que oferece, esquecendo-nos de que, quando se circunscreve o real da queda dos corpos numa lei matemática, algo nos é inevitavelmente subtraído - e esta subtração que a ciência realiza conta-se do lado do sujeito.

Com a ciência - como já mostrara Descartes pelo argumento do cogito -, ficamos desamarrados do Cosmos e reduzidos a um ponto fora do saber, sem extensão permanente, pois a ciência, em sua operação, por privilegiar o objeto a fim de reduzi-lo à objetividade, descola o sujeito das representaçôes que lhe conferiam um lugar estável (Benjamin, 1933/1985), depurando-o de tudo o que lhe assegurava estabilidade e consistência: fosse um lugar social definido, a referenciação de suas ações a um conjunto de valores dados ou mesmo sua corporeidade como intrínseca (coisa que a tecnologia médica, por exemplo, tratou de modificar).

Este trabalho trata da incidência da ciência, enquanto operação discursiva, no campo do sujeito a partir do curso da ciência na contemporaneidade e no domínio da clínica - e especificamente da clínica psicanalítica com adolescentes como práxis que dá lugar ao sujeito de que se trata em psicanálise. Sujeito do inconsciente, definido por Lacan (1965/1966) como o correlato heterogêneo e ineliminável da própria operação da ciência, testemunhado no plano da enunciação.

O que resulta da operação da ciência é um sujeito assubstancial e sem predicados (Milner, 1995). Um sujeito demarcado pela operação que lhe dá lugar. Sujeito apenas suposto, esvaziado de qualquer marca de positividade. Com o advento da ciência, pode-se dizer, o sujeito perde sua ancoragem e subsiste somente como ponto de fuga - reiterando permanentemente a operação que tenta reduzilo ao equacionamento pragmático dos mercados como variável calculável.

Porém o que se constata - especialmente na prática clínica, em qualquer instância - é que isto não é inteiramente possível. Isto só é possível até certo ponto. Algo resiste aí (é o sujeito); algo que não pode ser recuperado como identidade. O sujeito aparece e se faz contar no real como negatividade, descontínuo que não se deixa apanhar a não ser como pura diferença. Um sujeito, enfim, cujas manifestações costumam ter este caráter de corte, de alteridade com relação aos ideais da cultura que os sintomas evidenciam.

Os adolescentes, sem o saber, são os que, na contemporaneidade, experimentam com mais radicalidade esta condição de sujeitos desalojados das amarras simbólicas. Por conta da suspensão de seu lugar de sujeito (suspensão que define a própria adolescência) e por serem mais suscetíveis à transformação social e tecnológica, os adolescentes constituem uma espécie de vanguarda que testemunha com 
nitidez e contundência - em seus atos, suas patologias, problemas e dificuldades de toda espécie - o efeito desta incidência da ciência e do capitalismo em sua forma extremada atual sobre o campo do sujeito.

A adolescência nem sempre representou um papel tão importante na nossa história individual como hoje. Nem sempre esta passagem da infância à idade adulta durou tanto tempo, consumiu tantos esforços, gerou tanta mobilização social e institucional. Nas sociedades ditas tradicionais - aquelas, justamente, anteriores à subversão operada pela ciência moderna -, a adolescência podia ser simplesmente um período de transição e mesmo reduzir-se ao tempo de duração de certos ritos, postos em marcha aos primeiros sinais da puberdade, ritos que assinalavam uma passagem da família ao laço social mais amplo, ou, para dizer de outro modo, da infância ao posicionamento e identidade sexual.

Nossa época, no entanto, encorajada pela ciência e pela economia de mercado, assiste ao incremento desmedido da duração da adolescência - potencializado pela necessidade de regular o acesso ao processo produtivo. Um tempo que se infla, mantendo os jovens suspensos nesta condição "entre-dois" (infância/vida adulta), da qual parece cada vez mais difícil sair, e, de certo modo, condenando a adolescência a representar comumente, nos dias de hoje, uma crise - não apenas do ponto de vista subjetivo, mas também no que toca às alternativas discursivas que podemos oferecer ao adolescente.

Neste sentido, a adolescência é uma verdadeira metáfora da modernidade inaugurada com a ciência. Tempo que não deriva do simples e linear desenrolar dos dias, mas que advém de um corte - inaugural - no discurso, cujo efeito é de suspensão no campo do sujeito.

Segundo Melman (1997 e 2001), o adolescente é tomado como sujeito no desacordo existente entre a exigência de lidar com o encargo de sua identidade sexuada (que se coloca então de modo irreversível para ele) e um estatuto social que o subestima e o declara incapaz - porque, de fato, socialmente ele não possui os meios para assegurar sua emancipação. Confrontado com a necessidade de se fazer reconhecer, o adolescente contemporâneo não encontra no Outro da cultura - a quem doravante ele se dirige, alargando o campo que até então tinha sido o de seus pais ou responsáveis - o reconhecimento simbólico que poderia fazer seus estatutos subjetivo e social coincidirem com a maturidade biológica que lhe advém. Seu estatuto jurídico, por exemplo, em nada difere daquele da criança. Do ponto de vista jurídico, mesmo no Brasil, onde a lei tenta estabelecer um estatuto próprio do adolescente, a adolescência é o período da ambigüidade entre minoridade e maioridade, irresponsabilidade e responsabilidade (Brasil. Lei N. 8.069, de 13 de Julho de 1990, Estatuto da Criança e do Adolescente). 
Tendo que realizar por ele mesmo esse trabalho de amarração que outrora ficava a cargo dos ritos, e não podendo contar com os recursos que adviriam de uma instância simbólica que não lhe diz mais nada - desacreditada e fragilizada que está pelos ideais de certeza e exatidão introduzidos com a ciência -, o jovem sujeito terá que se fazer contar no real.

A ficarmos apenas nos exemplos à nossa volta, relacionados seja aos crimes anônimos cometidos todos os dias por jovens ligados ao narcotráfico, seja aos assassinatos brutais de ancestrais e outros, justificados pelos motivos mais banais - sem excluir os freqüentes e igualmente danosos (embora menos ruidosos) acidentes provocados por adolescentes que se expõem a situações de risco (passagens ao ato suicidas, explícitas ou não, "pegas", "roletas russas", gravidezes precoces ${ }^{1}$, etc) -, constatamos, em última instância, que tipo de intervenção um sujeito que tem que se fazer contar no real, fora do pertencimento simbólico, é capaz de produzir.

De modo geral, tendemos a tomar essas manifestações da crise adolescência - manifestações que dizem respeito e põem em causa nossa problemática relação com o sexo, com o gozo, com a morte - como redutíveis ao erro, à patologia, à imaturidade, etc que um pretenso estádio, que a maturidade permitiria ultrapassar ${ }^{2}$. Com mais fecundidade, tentamos isolar e identificar aí os vários elementos da virada subjetiva implicada na adolescência - reafirmação da escolha de objeto amoroso/sexual, apropriação ou refundamento da imagem do corpo em função não mais do olhar e da voz do Outro (da mãe, por exemplo), mas dos pares; reposicionamento do sujeito com relação aos ideais, etc. Porém isto não basta, pois o que estes atos atestam, o que nos obrigam a constatar - na maior parte das vezes com um assombro que nos faz nos sentir em atraso, defasados - é que o sujeito que emerge aí representa o que há de mais heterogêneo (e, no entanto) produzido no contexto dessa racionalidade liberal, pragmática e operatória que ele parasita e que é a nossa: a racionalidade inaugurada com a ciência moderna.

Dizendo de outro modo, se este sujeito aparentemente irracional, com quem tratamos, é heterogêneo à racionalidade científica, se ele é requisitado como ausente da operação da ciência e se, por outro lado, ele não pode ser inteiramente reduzido por ela senão ao preço de seu desaparecimento - o que faria dele um objeto -, é porque ele, sujeito, é o resto da operação da ciência (Lacan, 1965/ 1966). A questão que se impõe então, e à qual a patologização não responde verdadeiramente, é a de tentar identificar as razōes desta crise, levando-se em conta a articulação de suas manifestações ao funcionamento social contemporâneo ordenado pela ciência - tomando o momento inaugural da adolescência e o ad- 
vento da ciência como indicadores privilegiados da estrutura constitutiva do campo do sujeito.

A adolescência não é um conceito cabalmente estabelecido no vocabulário psicanalítico por várias razões, das quais a mais importante sem dúvida diz respeito à dificuldade de estabelecer se a adolescência é apenas uma manifestação fenomênica de uma transição biológica (o aparecimento de um novo corpo, com os atributos sexuais secundários) ou social (novos papéis, novas exigências que recaem sobre o jovem); ou se se trata de um processo determinante na estruturação do sujeito. Para o que concerne a este trabalho, falar de adolescência é falar de uma etapa lógica da articulação do sujeito na estrutura (Lacan, 1962-3/2004) definida pelo encontro com o real do desejo sexuado como aquilo que excede (Lacan diz ex-siste) a estrutura lógico-simbólica, recaindo ao encargo do sujeito desejar, assumir em nome próprio e à custa de sua própria condição de sujeito (Freud, 1924/1976 e Lacan, 1974/2001).

Por outro lado, a relação intrínseca, já mencionada, que a duração da adolescência tem com a nossa cultura exige que tomemos aí nossa própria responsabilidade, evidenciada pelo fato de que os problemas que se colocam na adolescência (e que a adolescência coloca) extrapolam o âmbito particular e póem em xeque o próprio laço social (e os princípios constitutivos da sociedade). Neste sentido, a aproximação a ser feita entre as questôes da adolescência e o funcionamento social mais amplo é de ordem ética.

Neste ponto, tomamos o caminho indicado por Melman (1997), que adverte que a crise psíquica que a adolescência representa na nossa cultura está ligada à ausência de uma sanção simbólica que pudesse situar para os jovens seu estatuto. E observamos que deixar ao sujeito toda a responsabilidade por sua sexuação, por sua implicação na vida sexual, muitas vezes à revelia da ordem social e familiar, é verdadeiramente um traço de nossa cultura, constituída pelo fato de que a ciência esvaziou o céu dos deuses, abolindo o lugar da transcendência como depositária do que falha na ordem do mundo e deixando ao sujeito o encargo de ter que responder por isso com sua subjetividade (Lacan, 1965/1966 e Melman, 2002).

Lacan refere explicitamente o sujeito da psicanálise ao sujeito da ciência. $\mathrm{O}$ que é curioso, porque justamente Lacan (1965) diz que a ciência foraclui o sujeito - referindo-se ao termo jurídico que remete à impossibilidade de integração (ou reintegração) de um dado termo da operação uma vez que seu ciclo se complete e referindo-se também ao termo utilizado por ele para traduzir o alemão Verwerfung, empregado por Freud para designar o modo de defesa próprio da psicose. Nesta, o sujeito, ao tentar livrar-se de uma idéia que o acomete, acaba por ter que arcar com o ônus do seu retorno - não como sonho, sintoma, ato falho, que são retor- 
nos que acontecem no registro simbólico da experiência do sujeito (caso o modo de defesa fosse o recalque neurótico), mas como "retorno desde fora"; retorno (no) real, jamais inteiramente simbolizável (Lacan, 1959/1966). Todavia, é importante notar que a noção de "foraclusão" vem justamente assinalar que não se trata, na irredutibilidade do sujeito à ciência, da heterogeneidade entre dois que não se interpenetram, não se mesclam, mas sim da heterogeneidade daquilo que numa operação é recusado, ejetado, aquilo que não deve participar do resultado antecipado da operação. Assim, quando Lacan se refere à foraclusão do sujeito pela operação da ciência, não se trata apenas do modo específico de exclusão promovido pela ciência e pelo jogo do capital, mas, igualmente, do efeito de retorno que pode advir daí. Então, o que nos importa pensar é o que pode implicar - para a clínica, para nossa formação social - este retorno no real do sujeito.

A clínica nos confronta com este retorno no real como o próprio do sujeito. Por esta perspectiva, a adolescência aparece como momento inaugural desta emergência do sujeito enquanto ruptura; limite que não se deixa capturar em nenhuma relação de identidade. Os adolescentes habitam, como se diz, este fio da navalha. Corte em que se equilibram precariamente os nem crianças, nem adultos, que não acharam ainda seu lugar, o lugar a partir do qual eles poderão efetivar sua participação e fazê-la reconhecer pelo Outro da vida social.

Sujeitos apenas na medida em que o sujeito não se pode antecipar, na medida em que ele emerge (sempre tarde demais) do real do ato - a clínica com adolescentes testemunha de modo dramático esta propensão ao agir (Utilizemos a expressão de Freud, 1914/1976, que reúne os acting-out, as passagens ao ato e os atos verdadeiramente fundadores de uma nova posição para o sujeito).

Diante da dificuldade de abordagem dessas manifestações intempestivas, comum aos profissionais que, a vários títulos, se encarregam de adolescentes, empreende-se todo um esforço na produção de definiçôes e diagnósticos que beiram por vezes um positivismo comportamentalista e elidem a questão, deixando escapar o próprio do caráter dos sintomas mais freqüentes no adolescente, considerados como sinal de uma estrutura, quando eles talvez não sejam senão uma experimentação da sintomatologia própria de um adulto.

$\mathrm{Na}$ contramão desta tendência, resta a alternativa de reconhecer uma discursividade própria a estes atos, situá-los como da ordem de um dizer. Há um dizer nas dificuldades encontradas na prática clínica com adolescentes, dizer que está necessariamente referido à ordem discursiva vigente introduzida pela operação da ciência. Porém, para aquilatar e recolher este dizer, a epistemologia - análise formal das operações constitutivas da ciência - não basta. É preciso evocar o campo da clínica como experiência que reintroduz "o dizer por trás daquilo que 
diz” (Lacan, 1973/2001: 449). É neste campo, através do que indicam as dificuldades ligadas à instalação da transferência ou os impasses em relação ao sexo e à morte daqueles que, justamente, estão em vias de tomar lugar (de sujeito) na vida social, que poderemos aferir as transformações de nossa relação com a linguagem e os limites sancionados para o gozo na contemporaneidade, em seus desdobramentos para o sujeito.

A operação de matematização do real que dá origem à ciência não é, como se poderia pensar erroneamente, a substituição de uma linguagem antiga (linguagem da natureza ou aristotélica) por outra (a linguagem dos caracteres matemáticos de Galileu). A matematização implica uma ruptura radical de nossa relação subjetiva com a linguagem (Baron, 1979/1985, Hottois, 1992, Koyré, 1966/1985). Basta tomar o que a ciência, para se constituir, impõe à linguagem e ao seu funcionamento (Sampaio, 2000a e 2000b) para constatar que a ciência não transforma apenas a realidade que nos cerca. Ela incide também, diretamente, na linguagem, impondo-lhe certos modos operatórios que acarretam remanejamentos importantes no plano dos discursos.

Estes remanejamentos atingem vários aspectos acionados pelo discurso e apóiam-se basicamente em dois golpes desferidos sobre a linguagem. Em primeiro lugar, a dissimetria radical de elementos e lugares que é inerente ao funcionamento da linguagem é, por assim dizer, "domesticada" na operação de substituição do sistema significante da linguagem ordinária, sustentado na diferença, pela axiomática matemática (que consiste no movimento automático de proposiçóes que se sucedem, encadeadas a partir da simples aplicação de regras "sem comando"). Tal efeito deve-se, em grande parte, à necessária redução da linguagem à lógica matematizada no uso e entendimento do funcionamento da linguagem que a ciência promove (Sampaio, 2000a e 2000b), com a conseqüente restrição (ou anulação) da ação daqueles operadores (como os chamados shifters e outros) que fazem com que a linguagem incida sobre ela mesma e se transforme, gerando diferença e dissimetria e os efeitos que lhes são próprios. Dado que estes operadores realizam justamente a função de demarcação do (lugar-tenente) sujeito na linguagem, pode-se aquilatar o efeito danoso de tal encaminhamento para a operação de representação do sujeito na linguagem.

Do mesmo modo, o imperativo de certeza matemática, correlato ao projeto científico, coloca no horizonte a promessa de erradicação do conflito pela exatidão. Sob tal imperativo, configura-se um domínio cada vez mais sólido da numeração, com a conseqüente abolição da questão sobre o sentido e o lugar do sujeito; e uma substituição, incisiva, porém silenciosa, da autoridade simbólica (habitualmente ligada ao lugar ou à função a partir da qual se exerce) pela atribuição de 
uma autoridade "natural" aos fatos. Autoridade que provém do modo de legitimação dos enunciados em função de sua coerência interna que é próprio da ciência. Os efeitos de tal imperativo vão, portanto, inevitavelmente na direção de um declínio do lugar atribuído à palavra e ao pacto simbólico na ordenação do laço social.

No campo da clínica, colhemos vários tipos de efeitos que permitem evidenciar e analisar estas transformações de nossa relação com a linguagem desencadeadas pela operação da ciência. As peripécias da transferência, na psicanálise com adolescentes, por exemplo, nos ensinam bastante sobre os efeitos da supervalorização, promovida pela ciência, do saber operatório. Valorização de um saber imediatamente verificável em suas aplicaçōes práticas, por oposição a um saber que seria teórico e passível de controvérsia.

Constatamos no plano subjetivo da clínica a dificuldade que esta relação com o saber introduzido pela ciência traz para a elaboração de uma demanda dirigida ao Outro (e, conseqüentemente, para a instalação da transferência). O saber operatório é geral, numérico, enquanto a suposição de saber atribuível ao analista - suposição que Lacan (1968/2001) situa como pivô da transferência - só pode aparecer referida não à posse de um conjunto de conhecimentos, mas a um saber particular sobre o sujeito. Juízo em tudo oposto ao conhecimento científico, na medida em que concerne à própria falha de saber que constitui o sujeito e o liga ao Outro de um modo intrínseco.

No domínio da técnica, por outro lado, perdemos esta referência à alteridade que nos atravessa e nos condena a uma relação com o saber sempre parcial e particular. Tornamo-nos facilmente sugestionáveis (Melman, 2002) - é notável a capacidade dos adolescentes de se fazerem representar pelo pertencimento a certos grupos, pela empunhadura de certas insígnias e marcas que mudam conforme o momento e se ramificam, se disseminam em rede -, porém é mais difícil haver transferência localizada e endereçada a outrem.

Podemos aferir com os jovens, igualmente, o efeito que este saber universal e numérico (saber que deteria a resposta incontestável, a última resposta) pode ter no que diz respeito à relação do sujeito com o sexo. Em que pese a emancipação que a laicização promovida pela ciência trouxe para este domínio, a separação entre o sexo e a procriação lograda pela tecnologia, e até mesmo a vulgata freudiana apropriada no sentido de uma emancipação do desejo - em que pese todo progresso -, a referenciação de si, de seu lugar no mundo e de seu sexo, agora a cargo do sujeito, torna-se um problema concreto (e infinito, insolúvel) para cada adolescente. 
Uma vez que a sexualidade humana passa pela necessidade de verificar sua identidade sexual - verificação que só pode se fazer pelo outro, por meio de uma troca simbólica -, não basta afirmar por si mesmo uma identidade sexual, é preciso que esta identidade seja reconhecida, validada pelo Outro. Melman (2001) mostra como, neste aspecto do que serve para o sujeito como critério de identidade sexual, nossa civilização industrializada e comercial produziu um deslocamento notável. Em lugar de reconhecer a identidade sexual do adolescente, atribuindo-lhe os encargos e/ou benefícios que adviriam do aparecimento de sua condição plenamente sexuada, fazemos a validação de sua identidade sexual depender de sua habilidade econômica (num "batismo" inteiramente estranho a todas as sociedades tradicionais). Mas, "em troca", oferecemos desde sempre ao sujeito a oportunidade de (é-se mesmo solicitado a isso) - no quadro de uma equilibração capitalista entre oferta e demanda - afirmar seu desejo como consumidor. Ora, o que se pode constatar a partir da clínica é que o reconhecimento do adolescente como consumidor o coloca numa espécie de identidade monossexuada, "unissex", dizem os anúncios, que gera muitas questóes para os jovens que começam a se engajar na vida sexual. Questões não somente existenciais, mas também no plano subjetivo, relativas a uma incapacidade subjetiva de tomar lugar na partilha dos sexos e assumir uma identidade sexuada.

Eis o paradoxo: de um lado, os adolescentes se mostram ultralivres na expressão de seu desejo e rapidamente exercem a vida sexual. Mas isso talvez se deva menos a uma validação discursiva de seu estatuto sexuado e mais ao fato de que existe para nós, acima das instâncias sociais e jurídicas, um mecanismo de reconhecimento social que dá ao adolescente um lugar de consumidor e o incentiva a exprimir seu desejo em termos de demandas de consumo e, através disso, afirmar sua posição sexual. Por outro lado, na medida em que a sexualidade deixa de ser regida pela inexorável disparidade entre o sujeito e o objeto - inexorabilidade em torno da qual se erigia o desejo e que, justamente, o equacionamento do desejo em termos de demanda vem encobrir -, o que se constata é que a satisfação sexual tornou-se, para os adolescentes, aleatória, contingente.

Não é acaso se tantos adolescentes vão buscar em substâncias químicas (aditivos, drogas, etc) os meios de acesso a esta satisfação. O que vemos na clínica é que muitas vezes eles não sabem como fazer diferente disso. A precocidade, por exemplo, com que adolescentes se exercem nas expressões sui generis da sexualidade pode ser vista como uma outra conseqüência de nosso liberalismo, digamos, comercial. Tratamos de assegurar um funcionamento social que se pareça o mais possível com a oferta variada de prazeres a serem colhidos - o que faz com que se 
ponham em busca de insígnias (“GLS”, "bi”, "S/M”, e todas as siglas imagináveis) que fazem as vezes de uma identidade sexual e de um pertencimento reconhecidos e dão margem a uma satisfação que talvez tenha mais um caráter de se fazer valer imaginariamente (como homem ou mulher ou " $n$ ") do que propriamente sexual.

E o que dizer das passagens ao ato em situaçôes de perigo - limite sempre mais ou menos constitutivo da problemática adolescente? Freud já indicava que a grande ruptura para o sujeito é passar da brincadeira, do domínio lúdico, àquilo que é do domínio do real, dizendo que "a antítese do brincar não é o que é sério, mas o que é real” (Freud, 1908/1976: 149). Como são os jovens justamente que estão mais confrontados com este tipo de passagem, pode-se delimitar em seus testemunhos eloqüentes os efeitos que tem para o sujeito a aproximação vertiginosa entre o real e o virtual que a ciência produz.

A relação que temos com os limites é profundamente alterada pelo remanejamento discursivo provindo da ciência. Quando a ciência substitui o real opaco da natureza pelos caracteres matemáticos, no dizer de Galileu, o real como tal é esquecido em proveito de um real matematizado, depurado até o ponto da letra - que codifica, que se substitui ao real. Em conseqüência, torna-se fácil e tentador confundir a extensão dos limites do possível com a superação do impossível. Como coloca Lebrun (1997), a começar pelo fato prosaico de que uma máquina de calcular indica que o resultado da operação de divisão de 10 por 3 é igual a 3,333... - ela não vai indicar nunca que a operação é impossível -, a categoria de impossível não tem mais lugar num mundo ordenado pelo algoritmo. É mesmo isso que a ciência faz, ela dá a entender que, se levarmos a conta longe o bastante, chegaremos a um resultado positivo, determinado (em suma, a um resultado final).

Quando observamos o engajamento dos adolescentes em um tipo de atividades motoras (Bungee Jumping, ou o "brinquedo" kabum dos megaparques de diversão ${ }^{3}$ ) e esportes radicais (como o surfe em grandes ondas, onde uma queda é fatal), ou tóxicas (drogas e outras substâncias), ou de exploração (ultraleve, parapente, etc), nas quais se trata expressamente de flertar com a morte, podemos constatar até que ponto este apagamento dos limites incide para o sujeito. Ao que parece, precisamos cada vez mais destes momentos extremos para saber que "realmente” estamos em algo. Momentos em que o perigo é real (apesar das garantias), não é pura aparência. Portanto, não somente em seus impasses, mas também (e justamente) em suas "brincadeiras" favoritas os adolescentes indicam que em nossa sociedade, sem notícia do impossível, a satisfação tem como limites apenas os limites reais da dor e da morte. Melhor dizendo: ir até o extremo periga tornar-se 
índice da satisfação experimentada e desafiar a morte talvez seja o único testemunho válido de que se foi longe o bastante, de que se foi até o fim (até o real).

A contribuição da psicanálise, portanto, por concernir ao domínio da clínica, e especialmente a partir das colocações de Lacan (1969-70/1991) a respeito do discurso como laço social constituinte do sujeito, permite superar o reducionismo que consiste em patologizar todas estas manifestações da adolescência contemporânea. Operando a partir desta fratura dos processos identificatórios, através dos quais os sujeitos buscam posicionarem-se na existência, e que a ciência torna problemáticos, a psicanálise recolhe o retorno do sujeito na forma da queixa, do sintoma, do impasse - mas não para simplesmente ater-se a advogar para este sujeito uma singularidade inefável (seria reconduzi-lo ao obscurantismo). Ao encontrar no inconsciente um saber equivalente ao saber da ciência, saber feito de letras que se conjugam para além da consciência, do sentido e do significado, e cuja incidência é real, a psicanálise pode constituir-se como formação discursiva que sustenta e destaca este sujeito depurado, descolado da identidade. Digamos como Lacan, em L'Étourdit (1973/2001), que a psicanálise recolhe o efeito sujeito, mas dá a ele o valor de resposta do real.

\section{REFERÊNCIAS BIBLIOGRÁFICAS}

Baron, E. M. (1979). História da matemática-origem e desenvolvimento do cálculo. Brasília: Ed. Universidade de Brasília, 1985.

Benjamin,W. (1933). Experiência e pobreza. Em Walter Benjamin-Obras escolhidas (trad. e org. Rouanet, S. P.) (pp. 114-119). São Paulo: Brasiliense, 1985.

Brasil. Lei N. 8.069, de 13 de Julho de 1990: Estatuto da criança e do adolescente.

Couto, M. C. V. (2001). Novos desafios à reforma psiquiátrica brasileira: necessidade da construção de uma política pública de Saúde Mental para crianças e adolescentes. Em III Conferência nacional de saúde mental - Caderno de Textos (pp. 121-130). Brasília: Ministério da saúde/Conselho nacional de saúde.

Freud, S. (1908). Escritores criativos e devaneios. Em Edição standard brasileira das obras psicológicas completas, vol. IX. Rio de janeiro: Imago, 1976.

- (1914). Recordar, repetir e elaborar (Novas recomendaçóes sobre a técnica da psicanálise II). Em Ediçāo standard brasileira das obras psicológicas completas, vol. XII. Rio de Janeiro: Imago, 1976. 
. (1924). A dissolução do Complexo de Édipo. Em Edição standard brasileira das obras psicológicas completas, vol. XIII. Rio de Janeiro: Imago, 1976.

Hottois, G. (1982). Lê règne de l'opératoire. Em Prades, J. (Org.). La technoscience (pp. 180-192). Paris: Harmattan, 1992.

Koyré, A. (1966). Études d'histoire de la pensée scientifique. Paris: Gallimard, 1985.

. (1966). Études Galiléennes. Paris: Hermann, 1986.

Lacan, J. (1959). D’une question préliminaire à tout traitement possible de la psychose. Em Écrits. Paris: Seuil, 1966.

. (1962-3). Le séminaire Livre X: L’Angoisse. Paris: Seuil, 2004.

. (1965). La science et la vérité. Em Écrits. Paris: Seuil, 1966.

. (1968). Proposition du 9 Octobre 1967 sur le psychanalyste de l'École. Em Autres Écrits. Paris: Seuil, 2001.

. (1969-70). O seminário, Livro XVII: O avesso da psicanálise, Rio de Janeiro: Jorge Zahar Ed., 1991.

. (1973/2001). L'étourdit. Em Autres écrits. Paris: Seuil, 2001.

(1974/2001). Préface à L'éveil du printemps. Em Autres Écrits. Paris: Seuil, 2001.

Lebrun, J.-P. (1997). Un monde sans limite. Ramonville Saint-Agne: Érès.

Melman, C. (1997). Os adolescentes estão sempre confrontados ao minotauro. Em Adolescência - entre o passado e o futuro (pp. 29-43). Porto Alegre: Artes e Ofícios.

. (2001). Qu'attend l'adolescent de la sexualité et de la mort? Journal Français de Psychiatrie, 14, 53-56.

. (2002). L'homme sans gravité: jouir à tout prix - Entretiens avec Jean-Pierre Lebrun. Paris: Denoël.

Milner, J.-C. (1995). L'ouvre claire - Lacan, la science, la philosophie. Paris: Seuil.

Sampaio, L. S. (2000a). A matematicidade da matemática surpreendida em sua própria casa, nua, na passagem dos semigrupos aos monóides. Em Sampaio, L. S. Lógica ressuscitada: sete ensaios (pp. 57-83). Rio de Janeiro: Ed.UERJ.

. (2000b). Outra vez a matematicidade da matemática. Em Sampaio, L. S.

Lógica ressuscitada: sete ensaios (pp. 85-103). Rio de Janeiro: Ed. UERJ.

\section{Notas}

1 Há um aumento significativo de gravidezes de adolescentes na realidade brasileira urbana contemporânea: foi de 50\% entre 1994 e 2001, segundo dados do Data-SUS e o IBGE. O que poderia sugerir uma validação do estatuto de adulto ancorada a partir do real nos casos 
em que há uma precariedade dos recursos simbólicos para este fim. Lebrun (1997, pp. 170171) menciona estudos do INSEE europeu nesta direção. Sobre dados do aumento de gravidezes na adolescência, no Brasil, Cf. Jornal O Globo de 11/05/2003.

${ }^{2}$ A organização da saúde mental no Rio de janeiro, por exemplo, até pouco tempo atrás desconhecia inteiramente a especificidade da adolescência (Couto, 2001).

${ }^{3}$ Dispositivos que permitem ao sujeito experimentar a sensação de despencar em queda-livre e o suspendem no último minuto, quando ele está prestes a se esborrachar no chão.

Recebido em 2 de janeiro de 2005 Aceito para publicação em 10 de junho de2005 